\title{
COMPUTATIONAL PREDICTION OF LOW IMPACT SHOCK PROPAGATION IN A LAB-SCALE SPACE BOLTED FRAME STRUCTURE
}

\author{
J. THOTA, M.B. TRABIA \& B.J. O'TOOLE \\ Department of Mechanical Engineering, University of Nevada, Las Vegas, USA.
}

\begin{abstract}
Bolted space frames are usually used to allow easy assembly and disassembly, as well as replacing defective components. Although the performance of bolted space frame structures under static loads is well understood, research on the shock propagation through these frames is limited. The focus of this study is to understand shock propagation through space frames, which is a critical factor when assessing the functionality of these frames. In this research, a lab-scale space frame structure, comprising hollow square members that are connected together through bolted joints is constructed. Non-destructive impact testing is carried out on this structure and the resulting acceleration signals at various locations are recorded. The objective of this work is to develop a finite element (FE) modeling approach that can reasonably replicate experimental results.
\end{abstract}

Keywords: Finite element, low impact, natural frequencies, shock response, space frame.

\section{INTRODUCTION}

Finite element analysis is broadly used for simulating the transient response of structures under dynamic loading. However, limited research is available in assessing the adequacy of the FE codes in modeling shock loadings across structures with bolted joints that are commonly used in the space frames of vehicles. It has been observed that load transmitted within an assembled structure, like a space frame, is influenced by the distribution of bolted joints in the space frame structure [1]. The authors of [2] reached a similar conclusion.

Of particular interest is the shock propagation within vehicles, which was the focus of several researchers such as [3-8]. Vehicles typically contain internal space frames, which are structures made of members joined together by bolts, rivets, pins, weld, adhesives and so on. These joints play a very important role in maintaining the structural integrity of a space frame structure. Transfer of shocks through joints has substantial influence on the dynamics of the structure as joints make major contributions to the damping of the structure $[1,9]$. Friction in bolted joints is one of the sources of energy dissipation in mechanical systems. Sandia National Laboratories has investigated energy dissipation due to micro-slip in bolted joints [10]. Song et al. [11,12] have developed an adjusted Iwan beam element (AIBE), which can simulate the non-linear dynamic behavior of bolted joints on a vibrating frame. The simulated and experimental impulsive acceleration responses had good agreement validating the efficacy of AIBE.

Different methods have been employed to determine the dynamic response of space frame structures. Studying the natural frequencies, modal behavior, and damping of a structure, which constitute its dynamic characterization, can yield a better understanding of the dynamics of the structure and its reliability [13]. The frequency response function (FRF), which is obtained from fast Fourier transform (FFT), is the common method for determining the natural frequencies and mode shapes of a structure [14]. However, a simpler procedure is to determine the natural frequencies of a structure directly from the FFT; the frequencies corresponding to the conspicuous peaks in the FFT signal are the natural frequencies of the 
structure [15]. Responses measured from impulsive loading (impact or blast) are typically accelerations, velocities and displacements at critical locations on the structure. While comparing the FE predictions with the experimental results, one of these measures is typically considered [16].

The objective of this work is to understand how to use FE to accurately model shock propagation through bolted space frames. Section 2 contains description of a lab-scale space frame structure that is built for this purpose. The members and joints of this structure are based on a proposed design for a military vehicle space frame structure. Section 3 explains the procedures for impact testing of the structure. A FE model of the structure is developed in Section 4. Section 5 compares the FE results with the experimental ones. Conclusions and suggestions for future work are contained in Section 6.

\section{LAB-SCALE SPACE FRAME}

The lab-scale space frame was in the form of a cube-shaped structure to help understand shock propagation along three orthogonal directions. Figure 1 shows a model of the structure whose overall length is $482.6 \mathrm{~mm}$. The cube was made of 12 hollow square-sectioned members that are connected by joints. This arrangement follows a proposed design of a military vehicle space frame [17], which was developed to allow speedy exchange of damaged member of the space frame.

Each joint was composed of two C-cross sectioned halves that enclosed two members, Fig. 2. Each half of the joint had two L-shaped orthogonal branches. The two halves were bolted to the two members they enclose. A third member was placed at the corner of the joint and an angle was used to enclose the third member and connect it to the joint through two bolts. The angle itself was bolted the two halves using two bolts. Therefore, six bolts are used in each corner of the cube. The length and outer width of the branches of a joint were 114.3 and $50.8 \mathrm{~mm}$, respectively. The frame members that were fully enclosed within the joints were $342.9 \mathrm{~mm}$ long, whereas those bolted to the angles were $482.6 \mathrm{~mm}$ long. Figure 3 shows the different sections used in the lab-scale space frame and Table 1 presents the dimensions of these sections.

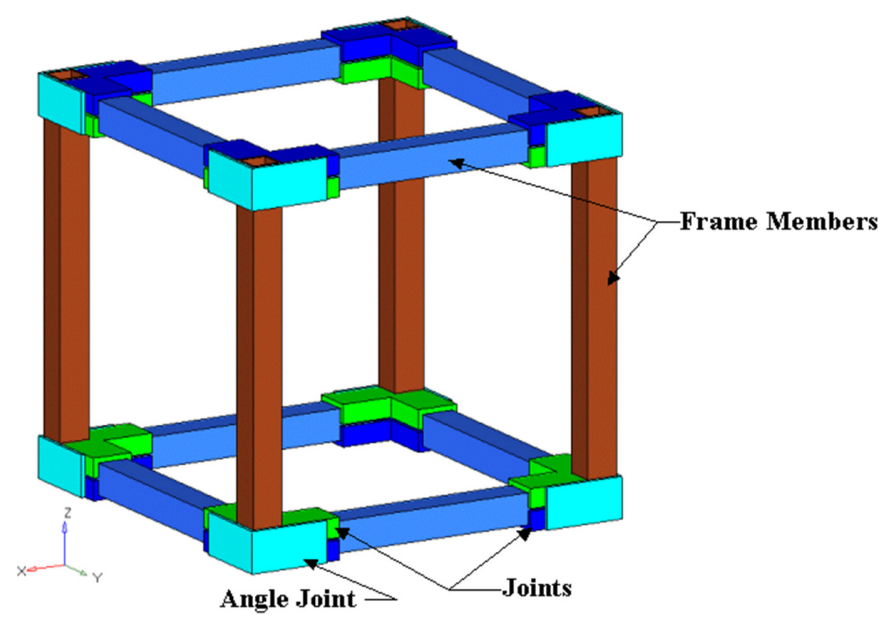

Figure 1: Model of the lab-scale space frame. 


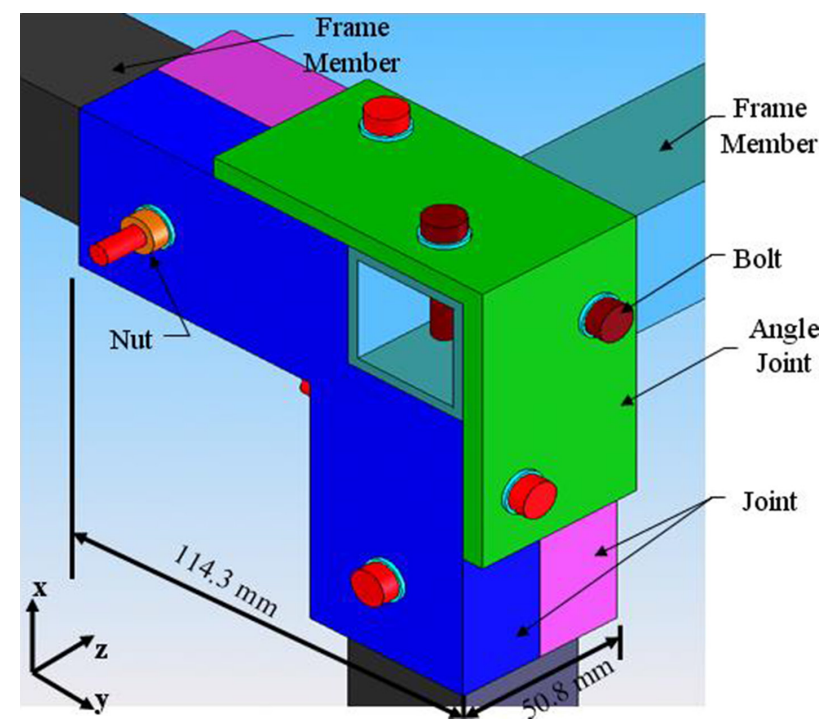

Figure 2: Model of the lab-scale space frame structure joint.

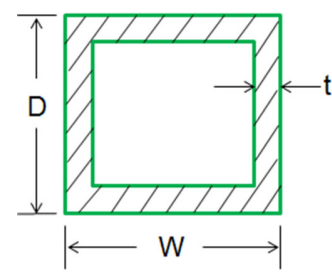

Frame member

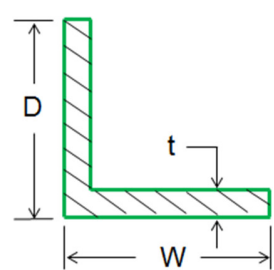

Angle Joint

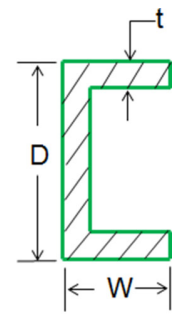

Joint half

Figure 3: Different sections of the space frame structure.

Table 1: Dimensions of the space frame structure sections (in $\mathrm{mm}$ ).

\begin{tabular}{lccc}
\hline Section type & D & W & t \\
\hline Frame member & 38.1 & 38.1 & 3.2 \\
Angle joint & 88.9 & 88.9 & 6.4 \\
Joint half & 50.8 & 25.4 & 6.4 \\
\hline
\end{tabular}

The frame members, joints, and angle joints were made of aluminum 6061 alloy. The material characteristics of this alloy are listed in Table 2. Steel SAE Grade $51 / 4$ inch coarse thread bolts were used throughout the structure. Relevant specifications of the bolts are listed in Table 3. The weight of the structure, including nuts and bolts, was $11.4 \mathrm{~kg}$. The assembled structure is shown in Fig. 4. The opposing surfaces of the joint halves were machined off by $1.6 \mathrm{~mm}$ (Fig. 5), so as to obtain a more uniform contact between the joint and the frame members. 
Table 2: Material properties of aluminum 6061 alloy.

\begin{tabular}{lc}
\hline Density & $2700 \mathrm{~kg} / \mathrm{m}^{3}$ \\
Modulus of elasticity & $68.9 \mathrm{GPa}$ \\
Poisson's ratio & 0.33 \\
Yield strength & $276 \mathrm{MPa}$ \\
Tangent modulus & $562 \mathrm{MPa}$ \\
\hline
\end{tabular}

Table 3: Bolt Specifications.

\begin{tabular}{ll}
\hline Proof strength of the bolt material $\left(S_{p}\right)$ & $586 \mathrm{MPa}$ \\
Thread tensile stress area of the bolt $\left(A_{t}\right)$ & $2.1 \times 10^{-5} \mathrm{~m}^{2}$ \\
Pitch diameter of the bolt thread $\left(d_{p}\right)$ & $5.525 \times 10^{-3} \mathrm{~m}$ \\
\hline
\end{tabular}

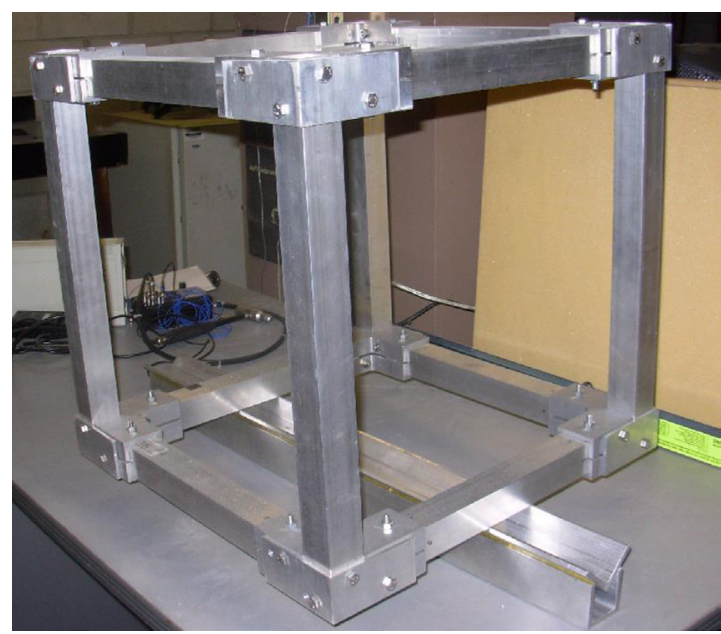

Figure 4: Aluminum space frame structure resting on an aluminum support.
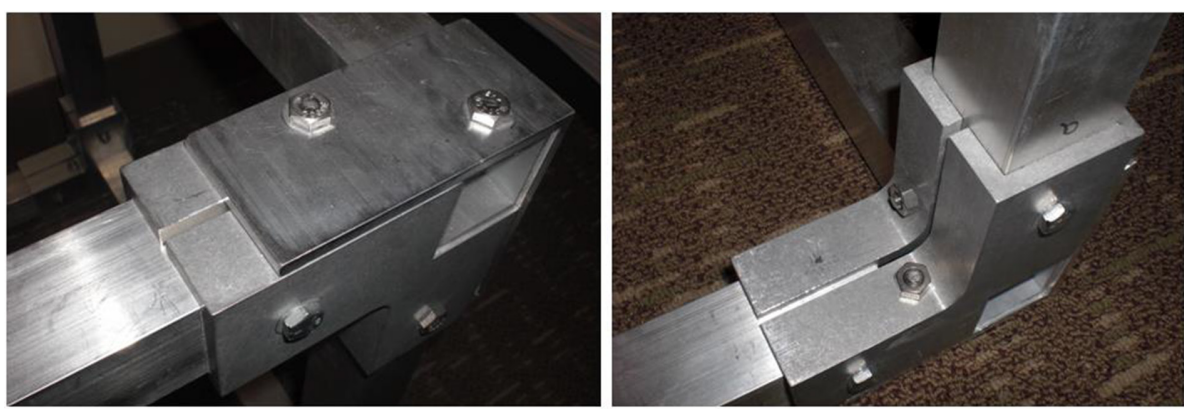

Figure 5: Machined joint halves. 


\subsection{Material model}

Although the impact hammer produced a limited force that would typically maintain the structure within the elastic region, it was decided to use an elastic-plastic bilinear model for the members in case localized plastic deformation occurs at the impact location and results in energy dissipation that may affect shock propagation. A MAT_PLASTIC_KINEMATIC material model, as defined in LS-DYNA [18], was used to describe the aluminum 6061 alloy. This material model is shown in Fig. 6.

\subsection{Tightening of joints}

The bolts were tightened to a specific preload to keep the experimental results consistent. Bolt tightening also reduced the noise in the output signals. These tightening force and torque values were calculated using the standard bolt design equations shown below [19].

$$
\begin{aligned}
F_{i} & =0.9 S_{p} A_{\mathrm{t}} \\
T_{i} & =0.2 F_{i} d_{p}
\end{aligned}
$$

where, $F_{i}$ is the bolt tightening force,

$S_{p}$ is the proof strength of the bolt material,

$A_{t}$ is the thread tensile stress area of the bolt,

$T_{i}$ is the bolt tightening torque,

$d_{p}$ is the pitch diameter of the bolt thread.

In this research, all bolts were tightened to a preload of $10.8 \mathrm{kN}$. To obtain this preload, a torque of $12.5 \mathrm{~N}-\mathrm{m}$ was applied to the bolts using a torque wrench.

\section{IMPACT EXPERIMENT}

The space frame was placed on an aluminum support (shown in Fig. 4), in all experiments. A member of the top of the frame member was impacted at a mid-point location with an instru-

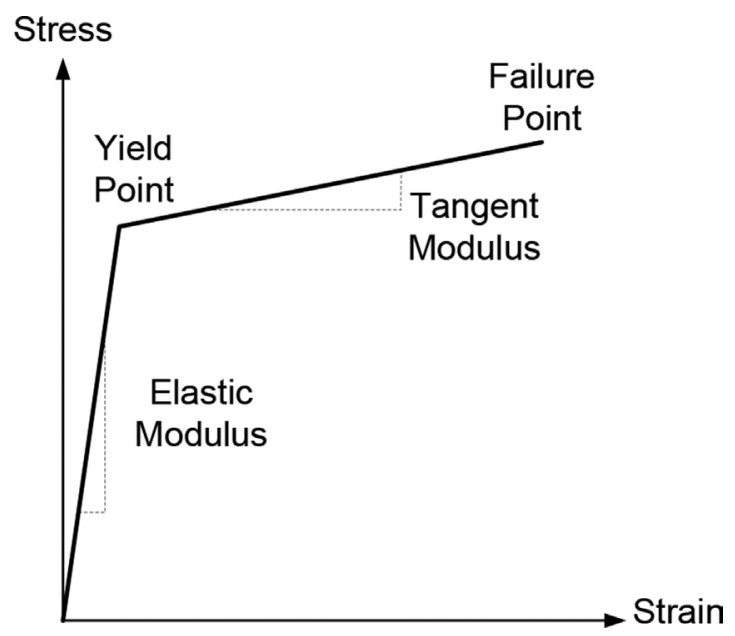

Figure 6: Material model defined for the FE analysis. 


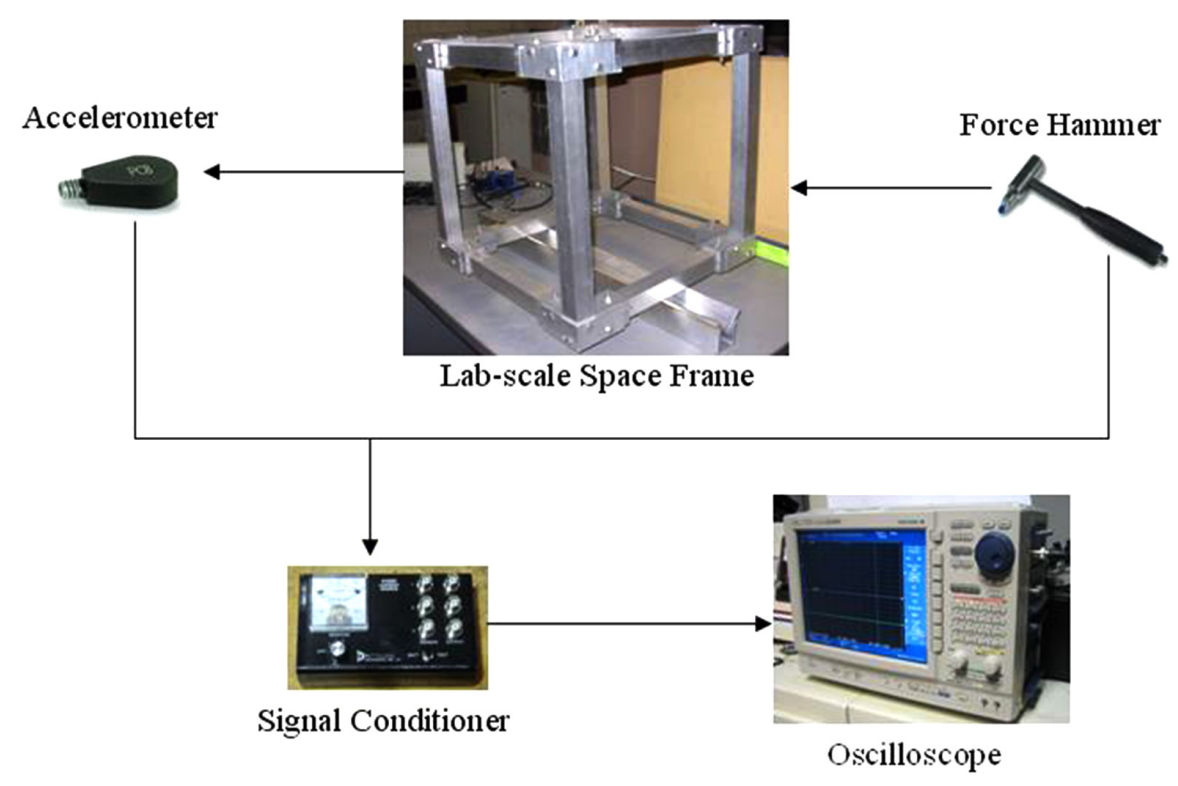

Figure 7: Impact experiment set-up.

mented force hammer and the acceleration was recorded using an accelerometer that was attached to the mid-point on the opposite side of the frame. A current source (signal conditioner) was used to supply voltage to the force hammer and the accelerometer. The output voltages obtained from the force hammer and accelerometer were converted into waveform and displayed by the oscilloscope. The sampling rate used for collecting data was $1 \mathrm{MS} / \mathrm{s}$. Figure 7 depicts the setup for the impact testing of the cube space frame. A MATLAB program was written to obtain the FFT of the acceleration waves, from which the natural frequencies of the cube space frame were determined.

\section{FINITE ELEMENT MODEL}

Initial attempts to use shell and solid elements provided inaccurate acceleration results due to the complexity of modeling contact between the various components of the space frame. It was therefore decided to use beam element to model the space frame as bolts were preloaded to the same tightness ensuring that all mating components behaved as a single body. Therefore, all components of the space frame structure were modeled using beam elements, which made the proposed approach simple and computationally inexpensive.

Altair HyperMesh version 9.0 was used to create the FE model of the lab-scale structure, whereas the explicit code LS-DYNA version 971 [18] was used to process the FE model. The length of each beam element was maintained at $3.2 \mathrm{~mm}$. The bolts and angle joints were not physically modeled in the FE model, but their mass was taken into account by adding mass elements, having the total mass of the bolts, nuts, and angle joint present at a joint location, to each corner of the cube, Fig. 8. The joints of the structure were modeled as two parts. The first part comprised the combined cross-section of the frame and the joint. The second part consisted of just the joint cross-section. These two parts were shown in blue and red colors in Fig. 9. The resulting model had 1832 beam elements. Common elements between different component 
faces were merged to obtain contact definitions between them. Four nodes on the bottom of the cube model were constrained, as shown in Fig. 8, to represent support of Fig. 4 where the cube was only restricted to move in the vertical direction (z-axis) during the experiment.

A typical experimental impact force signal was used to simulate the impact on the FE model, Fig. 10. The dynamic response of the cube space frame model was stimulated for $8 \mathrm{~ms}$. An Intel Xeon processor with $3 \mathrm{GHz}$ speed and $2 \mathrm{~GB}$ RAM approximately took $6 \mathrm{~min}$ to finish the simulation.

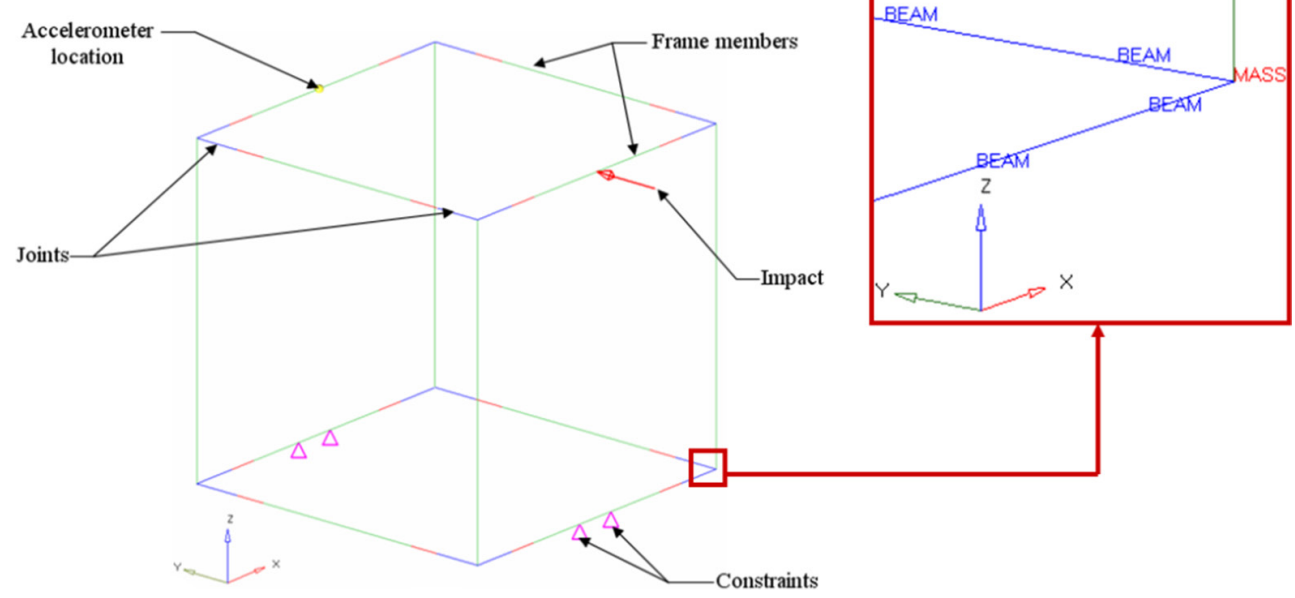

Figure 8: Finite element model of the lab-scale space frame structure.

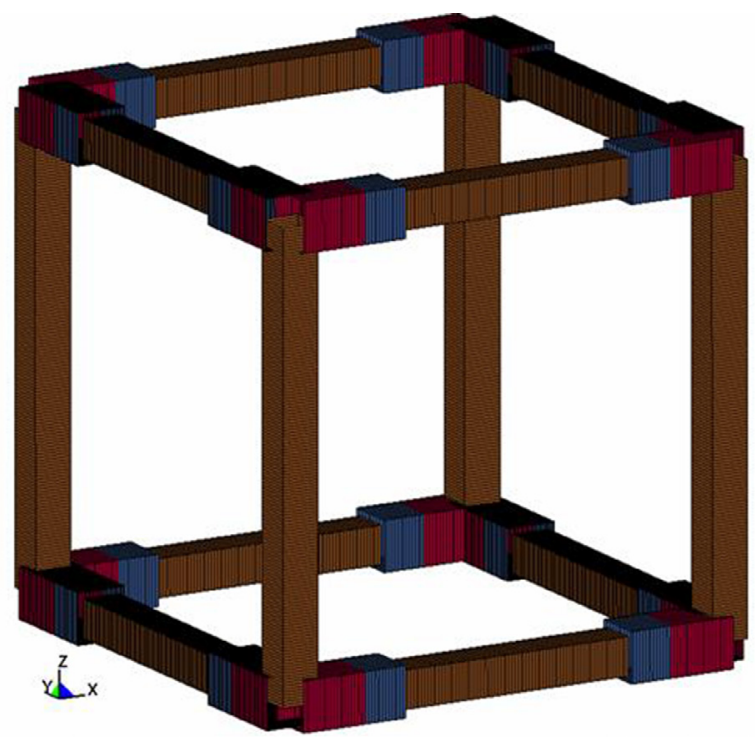

Figure 9: 3D representation of the beam elements (the 3D shapes are for illustration purposes only). 


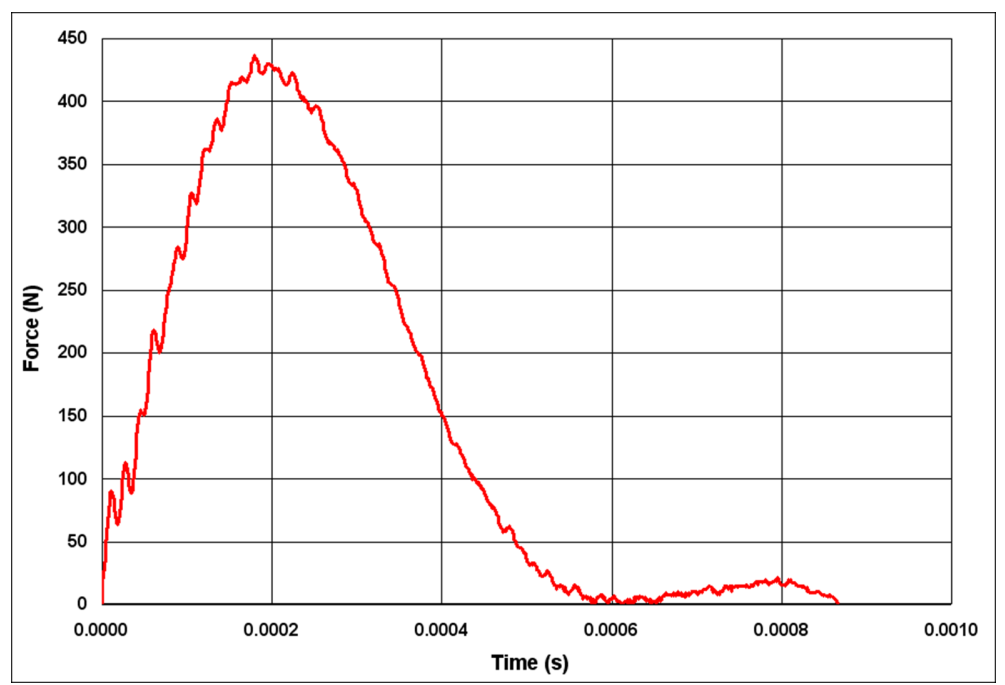

Figure 10: Typical experimental impact force signal.

\section{RESULTS}

Using a Butterworth low-pass filter, both acceleration signals were filtered at 10,000 $\mathrm{Hz}$, which was the limit of the accelerometer frequency range. Figure 11 compares the filtered acceleration signals. The figure shows that the FE acceleration signal accurately matches the first major peak of the experiment, with some deviation in the subsequent acceleration peaks, where those of the FE model are typically smaller than the experimental ones. This pattern is reversed in the last $2 \mathrm{~ms}$.

To better understand the acceleration results, experimental and computational FFT of the acceleration signals were developed. FFT of the experimental and simulated acceleration signals are shown in Figs. 12 and 13, respectively. Based on the FFT curves, the natural frequencies of the frame were extracted, (shown in Table 4). The first natural frequency of the experimental signal was $530 \mathrm{~Hz}$, whereas the simulated first natural frequency of the cube was $500 \mathrm{~Hz}$. The table shows that the FE model can predict the remaining experimental natural frequencies. Other results are close to each other, including the dominant natural frequency of $1500 \mathrm{~Hz}$. It was noted that the natural frequency of $810 \mathrm{~Hz}$ predicted by the FE model was barely visible in the experimental curve.

\section{CONCLUSIONS}

The objective of this paper was to propose an approach for modeling shock propagation through a space frame composed of bolted members and joints. A lab-scale space frame structure, in the form of a cube, was created. The frame was made of aluminum square hollow that are connected through a combination of joints and angles and bolted together. The final design comprised 36 structural components and 48 bolts, which were tightened to the same preload. Non-destructive impact experiments were conducted on the structure and the resulting accelerations were recorded. Modeling contact between the various components of the space frame is complex and computationally intensive. As all bolts were preloaded to the same tightness ensuring that all mating components behave as a single body, it was 


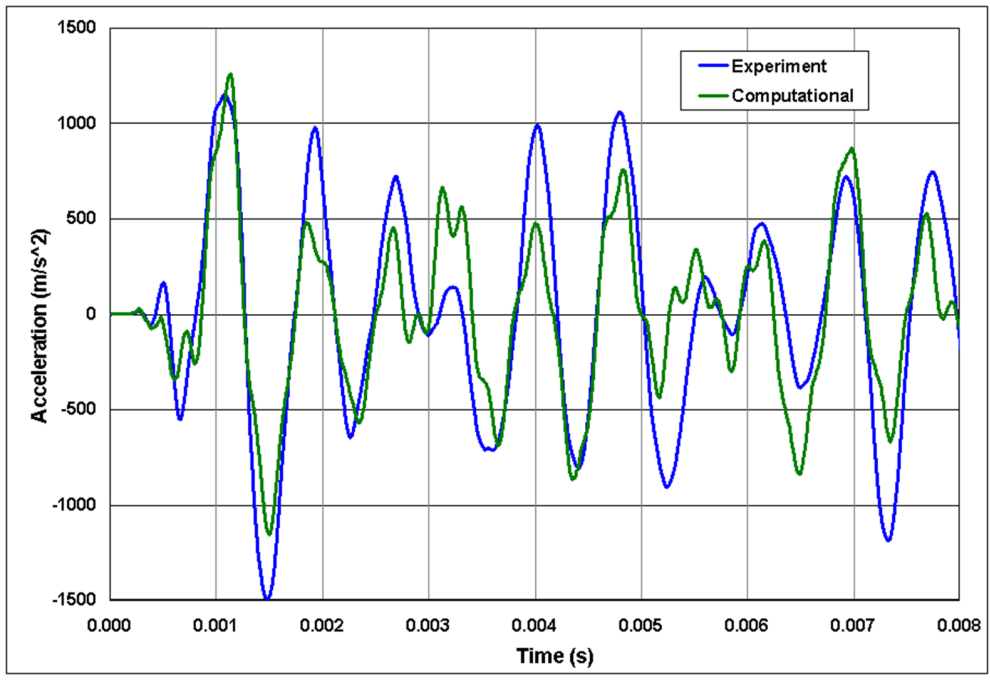

Figure 11: Filtered acceleration signals.

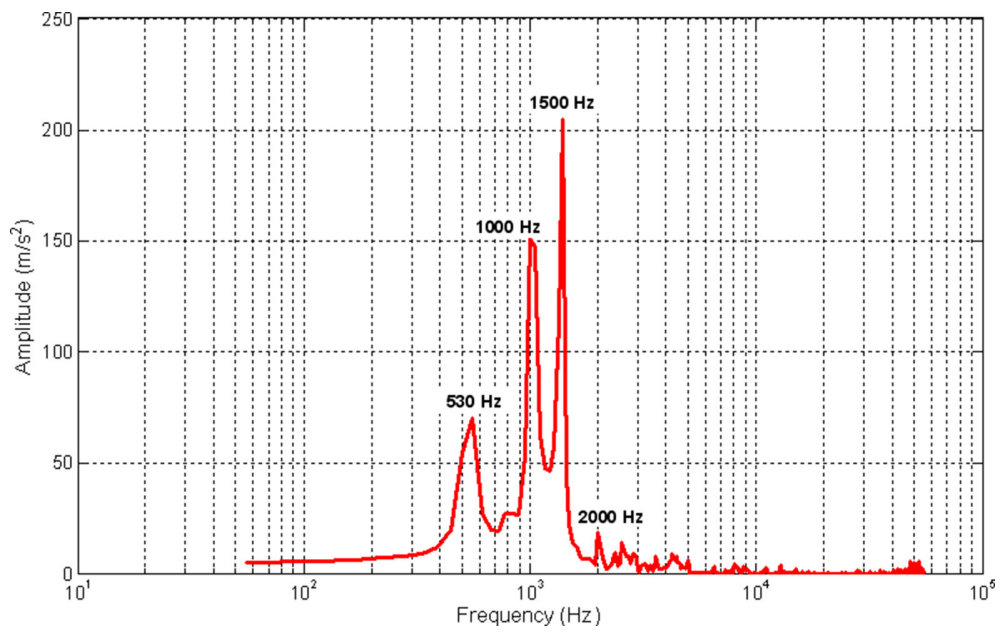

Figure 12: FFT of the experimental natural frequencies.

Table 4: Comparison of the FFT results $(\mathrm{Hz})$.

\begin{tabular}{lr}
\hline Experimental & FE \\
\hline 530 & 500 \\
800 & 810 \\
1000 & 1000 \\
1500 & 1500 \\
2000 & 2000 \\
\hline
\end{tabular}




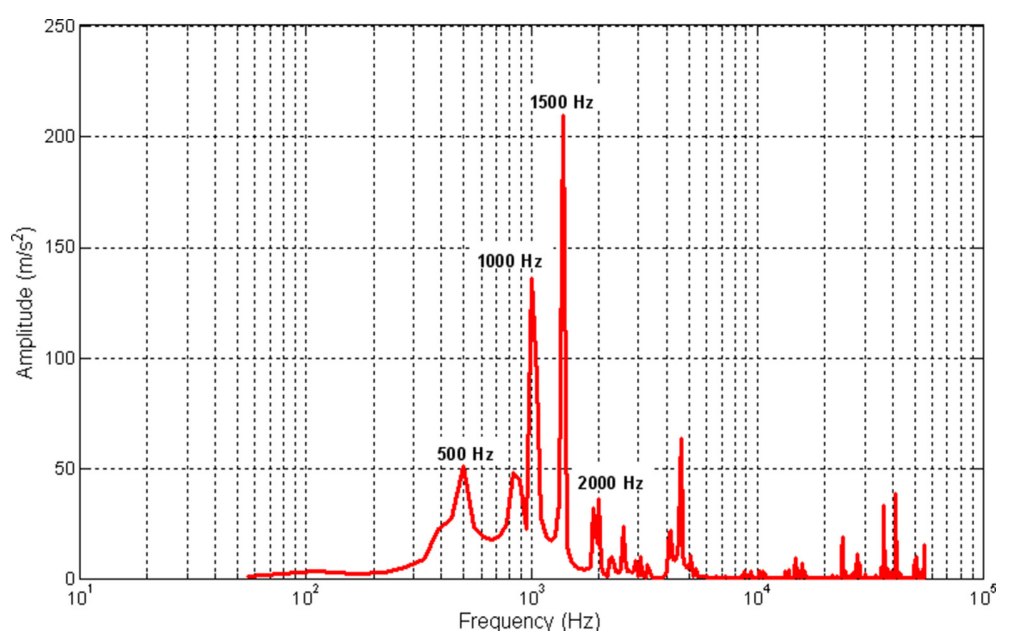

Figure 13: FFT of the FE natural frequencies.

therefore decided to develop a finite element model made entirely with beam elements. This model provided proof of combination of simplicity and accuracy that shell and solid elements do not provide. Overall, the simple beam model was able to accurately model this complex space frame. Simulated acceleration results were compared to the experimental data. The initial peak of the acceleration signal was captured by the FE model and the frequency of the predicted signal compares well with the experimental signal. To verify the results, a comparison of the FFT of the acceleration signals was conducted. The results show that natural frequencies, including the dominant natural frequency, match. Future research can include:

- Exploring ways to model the bolts individually.

- Mitigating transmitted shocks by optimizing the dimensions of the joints.

- Conducting impact experiment using drop weight towers or projectiles and adjust the model to allow predicting the transmitted shocks.

\section{ACKNOWLEDGEMENTS}

The authors would like to thank Mr. Ami Frydman, U.S. Army Research Laboratory, for suggesting this research topic and interacting with the authors. Dr. Douglas Templeton, U.S. Army TACOM-TARDEC, was helpful in developing the ideas of this research. This work is funded through a cooperative agreement with the U.S. Army Research Laboratory (ARL) under contract DAAD19-03-2-0007.

\section{REFERENCES}

[1] Gaul, L. \& Lenz, J., Nonlinear dynamics of structures assembled by bolted joints. Acta Mechanica, 125(1-4), pp. 169-181, 1997. doi: http://dx.doi.org/10.1007/bf01177306

[2] de Benedetti, M., Garofalo, G., Zumpano, M., \& Barboni, R., On the damping effect due to bolted junctions in space structures subjected to pyro-shock. Acta Astronautica, 60(12), pp. 947-956, 2007. doi: http://dx.doi.org/10.1016/j.actaastro.2006.11.011

[3] Goldsmith, W. \& Sackman, J.L., Energy absorption by sandwich plates: A topic in crashworthiness. In Proc. Symp. on Crashworthiness and Occupant Prot. in Transp. Systems, ASME, 126, pp. 1-30, 1991. 
[4] Das Gupta, A., Santiago J.M. \& Wisniewski H.L., Shock damage to sensitive components in an armored vehicle. Computers in Engineering, Proceedings of the International Computers in Engineering Conference and Exhibit, 2, pp. 153-161, 1992.

[5] Hassan, J.E. \& Frederick, G., Exact constraint design of vehicle components. SAE Special Publications: Sensors, Safety Systems, and Human Factors, pp. 55-62, 1996. doi: http://dx.doi.org/10.4271/961687

[6] Sicking, D.L., Reid, J.D. \& Rohde, J.R., Development of a sequential kinking terminal for W-beam guardrails. Transportation Research Record, 1647(1), pp. 89-96, 1998. doi: http://dx.doi.org/10.3141/1647-11

[7] Ahmed, A.K.W, Haque, M.M. \& Rakheja, S., Nonlinear analysis of automotive hydraulic mounts for isolation of vibration and shock. International Journal of Vehicle Design, 22(1), pp. 116-128, 1999. doi: http://dx.doi.org/10.1504/ijvd.1999.001862

[8] Heidari, M. \& Homaei, H., Estimation of acceleration amplitude of vehicle by back propagation neural networks. Advances in Acoustics and Vibration, Art. No. 614025, 2013, 2013. doi: http://dx.doi.org/10.1155/2013/614025

[9] Ibrahim, R.A. \& Pettit, C.L., Uncertainties and dynamic problems of bolted joints and other fasteners. Journal of Sound and Vibrations, 279(3), pp. 857-936, 2005. doi: http:// dx.doi.org/10.1016/j.jsv.2003.11.064

[10] Lobitz, D.W., Gregory, D.L. \& Smallwood, D.O., Comparison of finite element predictions to measurements from the sandia microslip experiment. Proceedings of International Modal Analysis Conference (IMAC) XIX, 2, pp. 1388-1394, 2001.

[11] Song, Y., Hartwigsen, C.J., Bergman, L.A. \& Vakakis, A.F., A phenomenological model of a bolted joint. Proceedings of the 2002 American Society of Civil Engineers, Engineering Mechanics Conference, pp. 1-8, 2002.

[12] Song, Y., Hartwigsen, C.J., McFarland, D.M., Vakakis, A.F. \& Bergman, L.A., Simulation of dynamics of beam structures with bolted joints using adjusted Iwan beam elements. Journal of Sound and Vibration, 273(1), pp. 249-276, 2004. doi: http://dx.doi. org/10.1016/s0022-460x(03)00499-1

[13] Tao, Z., Zhao, R.J. \& Yao, G.Q., Analysis and study on the static and dynamic behaviours of jointed parts. Proceedings of the 25th International Tool Design and Research Conference, pp. 363-367, 1985.

[14] Pilkey, D.F., Park, G. \& Inman, D.J., Damping matrix identification and experimental verification. Proceedings of SPIE on Passive Damping and Isolation-The International Society for Optical Engineering, 3672, pp. 350-357, 1999. doi: http://dx.doi. org/10.1117/12.349797

[15] Semke, W.H., Bibel, G.D., Jerath, S., Gurav, S.B. \& Webster, A.L., A dynamic investigation of piping systems with a bolted flange. ASME Pressure Vessels and Piping Conference, American Society of Mechanical Engineers, 440, pp. 121-128, 2002. doi: http://dx.doi.org/10.1115/pvp2002-1270

[16] Sabuwala, T., Linzell, D. \& Krauthammer, T., Finite element analysis of steel beam to column connections subjected to blast loads. International Journal of Impact Engineering, 31(7), pp. 861-876, 2005. doi: http://dx.doi.org/10.1016/j.ijimpeng.2004.04.013

[17] Thota, J., O’Toole, B.J. \& Trabia, M.B., Optimization of shocks within a military vehicle space frame. Structural and Multidisciplinary Optimization, 44(6), pp. 847-861, 2011. doi: http://dx.doi.org/10.1007/s00158-011-0685-0

[18] Hallquist, J.O., LS-DYNA Keyword User's Manual, Livermore Software Technology Corporation, 970, 2010.

[19] Juvinall, R.C. \& Marshek, K.M., Fundamentals of Machine Component Design, vol. 83, John Wiley \& Sons, Inc.: New York, pp. 418-423, 1999. 